\title{
Improving MSW Management through Recycling
}

\author{
Grace P Sapuay* \\ President, Solid Waste Management Association of the Philippines, Philippines \\ *Corresponding Author: Grace P Sapuay, President, Solid Waste Management Association of the Philippines, Philippines.
}

Received: April 26, 2019; Published: July 19, 2019

DOI: 10.31080/ASAG.2019.03.0581

\begin{abstract}
Recycling has been a by-word in the modern world as virgin resources are becoming scarce. As the population grows, so do the demand for a variety of consumer goods, the packaging of which, will most likely end as garbage. Indeed, municipal solid waste has been increasing at an alarming rate. Local governments are hard put at trying to come up with strategies to contain the massive generation of municipal solid waste. One way to improve management of municipal solid waste is through recycling. This helps to reduce the volume of waste being disposed in the landfill and divert the solid waste to recycling companies. It also gives a new form of livelihood to the poor people who could not find a job. Nowadays, most of the materials being used for production are made from recycled materials. Specifically, plastic waste is the single most problematic material in the waste stream. Plastic materials from packaging are highly recyclable, yet most people discard them randomly just about anywhere. The Philippines, for example, has been mentioned as the third largest producer of plastic waste in Asia. There is an on-going campaign to prevent plastic waste from going into the oceans as these are almost choking with plastic waste. To do this, an efficient and sustainable strategy to recover plastic waste for recycling will surely help to reduce and divert this type of recyclable waste away from the seas, from landfills and from the environment. This will greatly help to improve municipal solid waste management
\end{abstract}

Keywords: Solid Waste; Recycling; Municipal Solid Waste Management

\section{Introduction}

Solid waste generation is a function of population. The more people there are, the more solid waste is generated. Currently, the world has breached the seven (7) billion mark. Seven billion people consuming so much resources every day. Seven billion of people generating garbage every day. It means that if we do not make lifestyle changes, we will be using up all the earth's resources in no time at all. This is the reason why we need to recycle. Garbage piles up in landfills and is using up more space than we could afford. Solid waste is using more space of land that is best suited for other land uses such as agriculture, housing, parks, forests, and other such uses that are more important than just filling up garbage that contaminates the soil, air and water around us. Landfills are also known to contaminate groundwater. For example, older landfills, which have been sited close to surface waters or over aquifers and water tables have been found to contaminate these sources of water [1].
Sanusi [2], in his Master's thesis, studied the groundwater quality at Olusosun landfill in Lagos Nigeria and found that metals and other contaminants have migrated to the groundwater. Metals mentioned here are heavy metals such as lead, cadmium, manganese, etc. In another study by Mor., et al. [3] have found significant contamination of groundwater in an area near a landfill in India. Such studies lead us to rethink our wasteful lifestyles in order to conserve the quality of our groundwater and prevent future contamination. To lessen the impacts of solid waste on our soils, air and water, we have to reduce, reuse and recycle our solid waste. Most importantly, we should recycle what can be recycled, for example, plastic waste. This type of waste is currently a hot topic all over the world because of its effects on our oceans, impacting marine life, birds, whales, mammals, and many other creatures that depend on the sea for food, including humans. That plastic waste is a highly recyclable material should make us think twice before discarding these materials into landfills. These materials can either be reused 
or recycled to create new products, thus, saving on virgin materials as well as prevent them from drifting into surface waters that end up in the seas. Another material that is a cause for concern, the one that gives off methane when it biodegrades in the absence of oxygen is the organic waste - biodegradable materials that can generate methane gas and given off by landfills in the atmosphere, adding to the greenhouse gases that contribute to global warming and the consequent climate change. These materials can be taken out of the waste stream and converted into energy through bio-digesters or composted to be used as soil enhancers. Indeed, solid waste or most of the composition of solid waste are reusable and recyclable. For example, in the Philippines, an estimate by the National Solid Waste Management Commission [4] reveals that 27.78\% of MSW stream in the Philippines are composed of recyclable materials (see Figure 1).

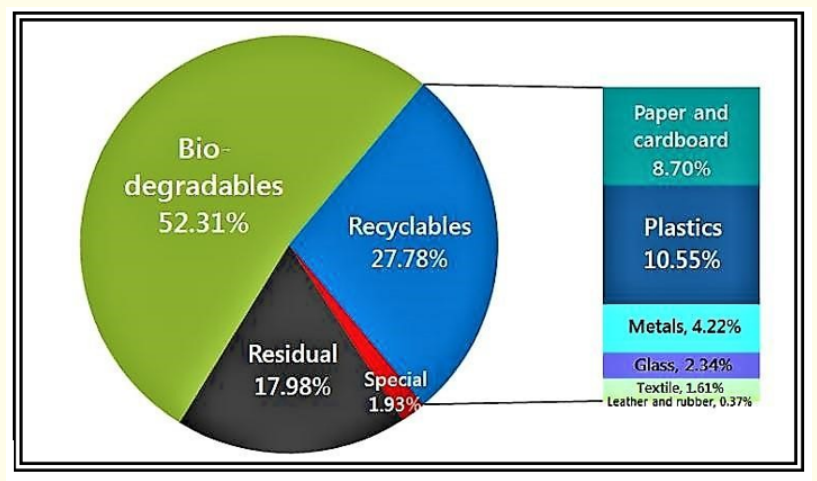

Figure 1: Composition of MSW in the Philippines. (Source: NSWMC 2016)

The presence of a high amount of biodegradable materials and recyclable materials means that $70 \%-80 \%$ can be diverted from the landfills and taken out of the waste stream and made into more useful materials. Only a small portion, about $18 \%$ should be discarded into the landfill. This means that if all these recyclables are recovered and all biodegradables are diverted from the disposal facilities, we would have prolonged the life span of our disposal facilities in the Philippines and improved solid waste management considerably as well as improve sustainability.

\section{Objectives}

This paper aims to show the importance of recovery of materials in the waste stream and how recycling can improve management of municipal solid waste.

\section{Approach and methodology}

This paper was written based on online sources as well as personal observations of the author during her work as a solid waste management consultant.

\section{Issues on recycling}

Increases in population all over the world has resulted in higher demands for consumer goods all over the world. This means that we are using up the earth's natural resources at a faster pace than in the past decades. The emergence of new communication technologies, coupled with the convenience that people have adapted in the current decade has also resulted in more waste, most of them plastic and other recyclable materials, has created a tremendous pressure not only on the Earth's resources but also on the local governments in terms of cleaning up their respective communities, as well as the shorelines. It has also added up to the worries that the waste has now occupied the seas and oceans where all discarded materials, especially plastic have ended up. Plastic bottles made of polyethylene terephthalate (PET) for example, has been seen in every place where humanity has walked, be it forests or beaches. The trouble with convenience is that it has created a society of disposables and instant gratification. So, people gratify themselves instantly when they want to dispose their waste just about anywhere. Plastic waste has been found to be the most numerous of all the wastes discarded and ended up into the sea. The invention of plastic waste, with its consequent convenience has also subsequently created a global problem: that being disposable, has found its way into every nook and cranny of the planet earth, be it in the mountains or into the sea, as shown in the figure 2 below.

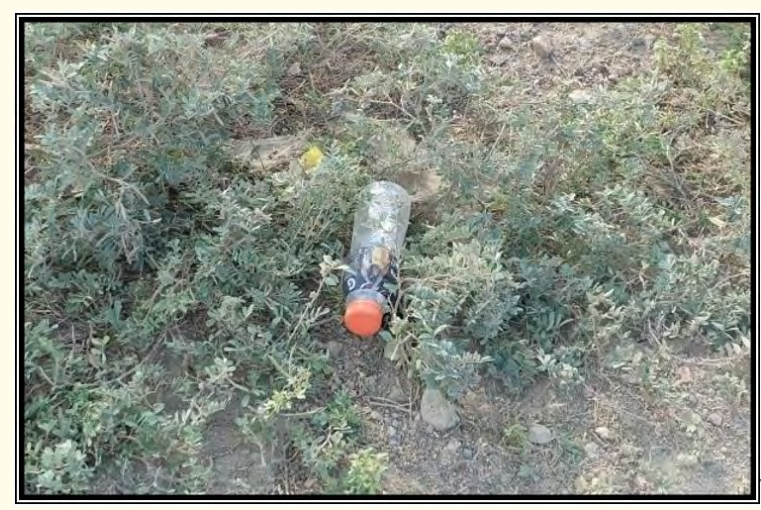

Figure 2: Discarded PET bottle in a mountainside. 
Such careless behavior, rampant among people, in utter disregard for the environment does not bid well for all of us. They must be made aware that waste can be recycled so they must be disposed of properly and not just randomly discarded whenever they want to. This is the number one issue in the entire world with regards to recycling: difficulty of recovery.

\section{Current situation of solid waste management in the Philippines}

Republic Act 9003 has mandated waste segregation to separate recyclables from non-recyclable waste at source. However, due to the minimal implementation of waste segregation among local government units (LGUs), collection of mixed waste is still being done and in an inefficient manner due to budgetary issues. For example, barangays (the smallest administrative unit in the Philippines), would oftentimes have only one truck to service the entire village. Collecting mixed waste means there is more garbage to collect, such as the one shown in the figure 3 below:

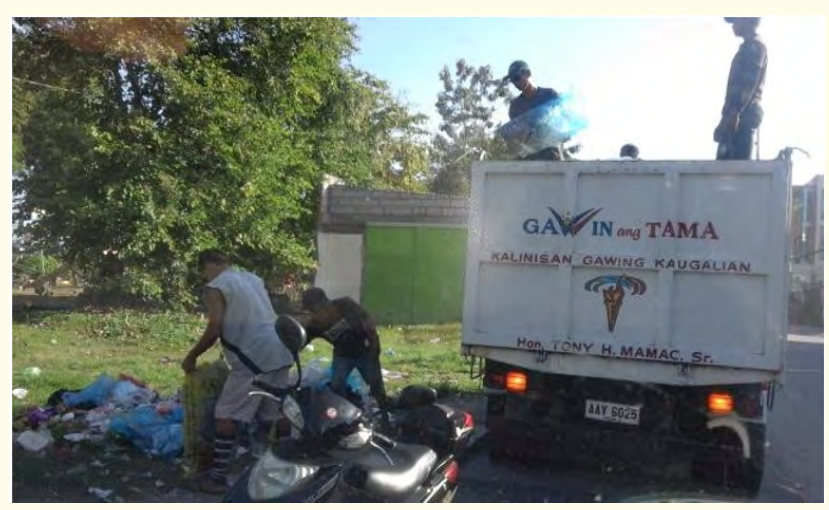

Figure 3: Mixed waste without receptacle.

In terms of disposal, without segregation to take away the recyclable portion, the disposal facility, which in the case of the Philippines, is mostly open dumpsite, gets filled easily, which is a critical problem since there is not much land for dumping garbage. In most cases, the dumpsite becomes a hazardous place, but becomes a haven for informal waste pickers, whose livelihood is to pick waste in the disposal facility or even in existing transfer stations such as in the one shown in Figure 4.

Indeed, the Philippine solid waste system is oftentimes dominated by the informal waste sector as the unsegregated waste gives them the opportunity to gather recyclable materials, which they sell to recyclers and junk dealers. The lack of a formal recycling system gives rise to the presence of informal waste pickers. All over the Philippines, where there are dumpsites, there are waste pickers also.

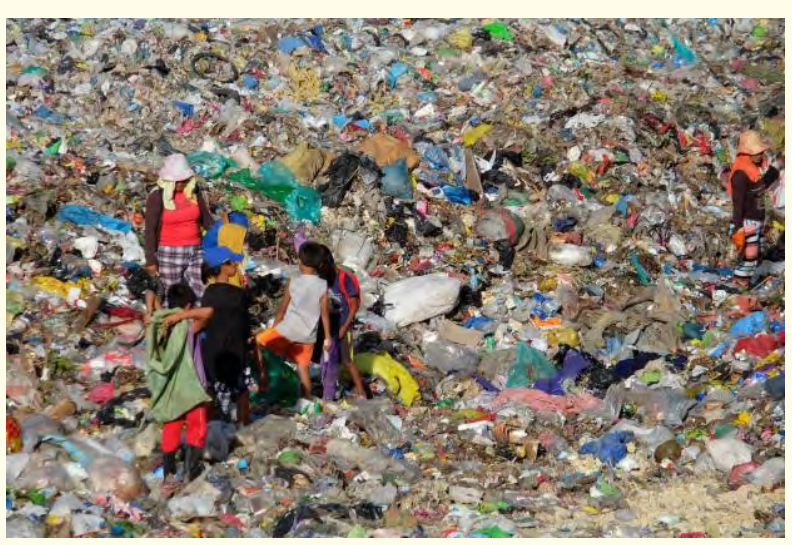

Figure 4: Informal waste pickers glean from garbage in a disposal site.

\section{Manufacturing and recycling}

Most of the waste products these days come in the form of packaging waste. More and more packaging materials end up as waste, such as plastic packaging, cardboard boxes, and other packaging that comes in a box almost always end up as waste. These packaging materials are mostly recyclable materials, especially plastic waste and cardboard boxes.

Industrialization and manufacturing has spurred the growth of economies on a global scale. This has led to generation of jobs, high income rates and consequently improvement of people's lives. These developments have led to high consumption rates and led to high generation of waste from manufactured packaging. Indeed, the more people consume, the more people discard (Medina, 2007). The figure 5 below shows the market share of food packaging materials.

It can be seen from Figure 5 that paper and board occupy the highest portion of food packaging materials at $34 \%$, whereas rigid plastic makes up $27 \%$ of food packaging, materials, while flexible plastic makes up $10 \%$ of packaging materials. Combining plastic packaging (rigid and flexible), would therefore make up 37\%, much higher than paper and board. It is no wonder that waste disposal sites are dominated by plastic packaging waste. Such wastes are highly recyclable in many developed countries but sometimes offer no market in the Philippine setting.

\section{Global recycling rates}

Recycling is empowering to consumers and, in the case of traditionally recyclable materials such as glass, paper, rigid plastics and certain metals, economically viable. Recycling not only diverts 


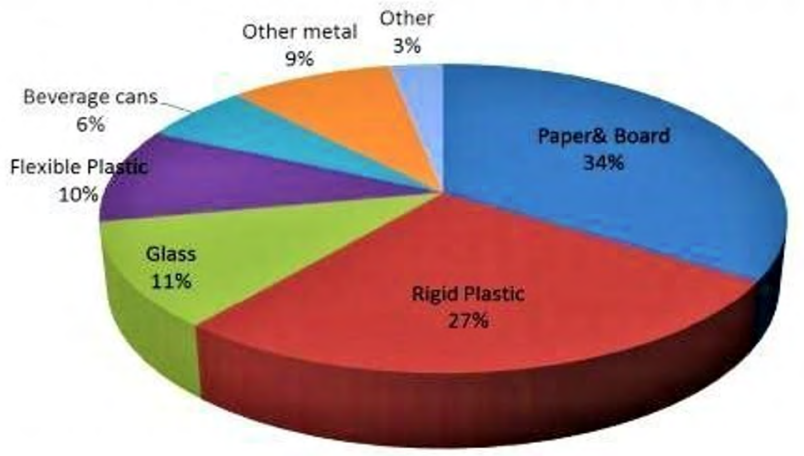

Figure 5: Market share of food packaging materials (Source: Food Packaging Forum).

potentially valuable materials from landfills and incinerators, it also offsets demand for virgin materials, helping to keep carbon in the ground. Recycling aligns human consumption with nature's activities [5]. So that in highly developed countries, especially in Europe, formal recycling programs have been well-established. For example, in 2013, Germany (65\%) topped the world's recycling rates, which included composting as a form of recycling the biodegradable waste, and followed by South Korea at 59\%, Slovenia and Austria came in third at 58\% recycling rate, while Belgium came fourth at $55 \%$ and Switzerland (51\%). These top 5 countries have been working well on their recycling programs.

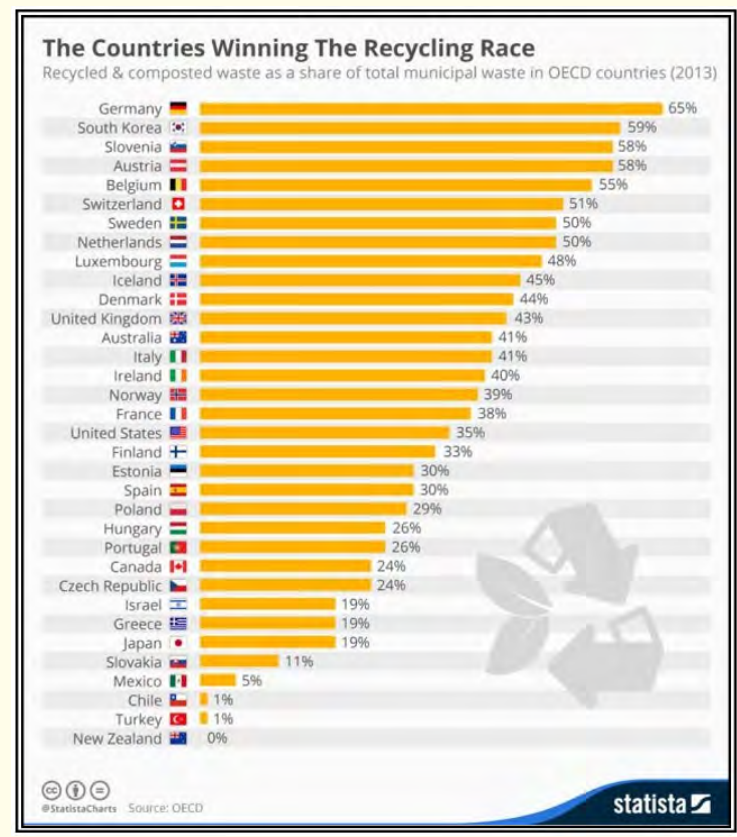

Figure 6: Countries winning the recycling race in 2013 (Source: weforum.org).
Recycling rates are not constant and varies every year by country to country, depending on various factors. For example, by 2015 , Austria topped the world's recycling rate at $63 \%$, followed by Germany at $62 \%$, Singapore, 59\%, South Korea, 49\%. These were the top 4 countries with the highest recycling rates all over the world. The pictographic (Figure 6) shows the countries with the highest recycling rates in 2015 .

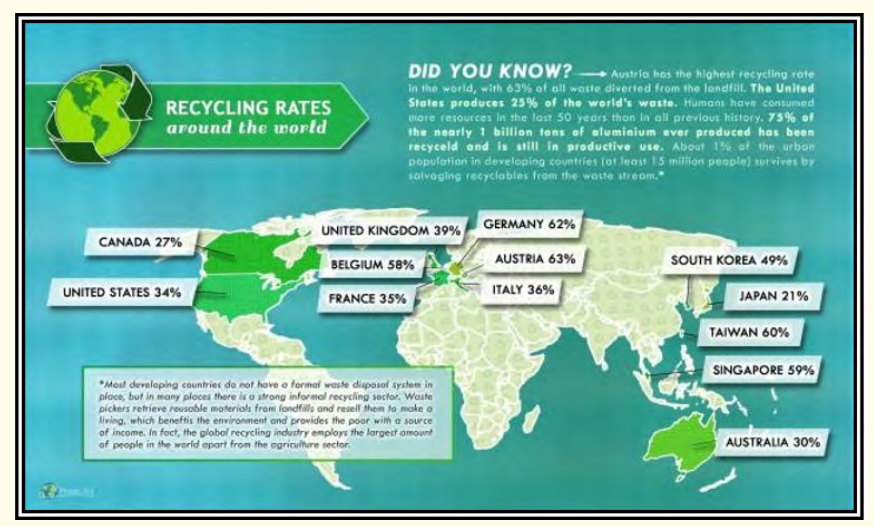

Figure 7: Pictographic of countries with the highest recycling rates around the world in 2015 (Source: planetaid.org).

In 2017, however, Germany has outperformed Austria n recycling rates, although at a lower rate than 2015 at $6.1 \%$ and $53.8 \%$ respectively, closely followed by South Korea (53.7\%) and Wales at $52.2 \%$ [6]. Figure 8 below shows the top 10 countries with the highest recycling rates in 2017.

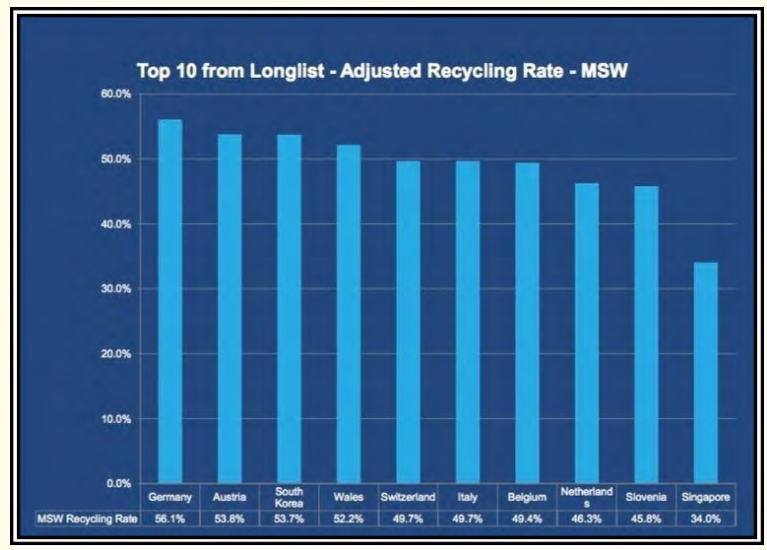

Figure 8: Top 10 countries with the highest recycling rates in the world. 
In the United States, out of the 258 million tons of solid waste generated in 2014, over 89 million tons were recycled and composted (34.6\%), while 33 million tons (52.6\%) were sent to the landfill and incinerated. Also, 66.4 million tons or a quarter of the total MSW were recycled [7].

The case is different in emerging economies in Asia and Latin America, where recycling is dominated by the informal sector, since there is no formal recycling program. The informal waste sector forms the base of the recycling chain in these countries and local governments benefit from the free diversion of waste through the informal waste sector. This lack of formal recycling programs means that more recyclables are being discarded.

\section{Plastic waste recycling}

Recycling of plastic waste was mostly done in China. Plastic waste is among the most highly recyclable of all materials that end up as waste. Why do we need to recycle plastic waste? Because there's so much of it that end up in the environment, causing so much toxicity around us. In the sea, they are mistaken for food by various marine organisms, among them the world's largest creatures, the whales. Some have ended up dead on the beach, dead because of plastic ingestion. According to the Northern California Compactors Company's website, $90 \%$ of the waste accumulated by municipal corporation is plastic waste. In Europe plastic has been produced and used in huge amounts, ending up as waste such as the one shown in Figure 9. Recycling plastics help save a lot of energy and natural resources as these are the main ingredients required for making virgin plastic. Saving petroleum, water, and other natural resources help conserve the balance in nature. Another thing is that it clears up landfill space. Also, various experiments have proven that when another waste material is thrown on the same ground as plastic waste, it decomposes faster and emits hazardous toxic fumes after a certain period. These fumes are extremely harmful to the surrounding area as they can cause different types of lung and skin diseases.

Plastic waste recycling helps promote plastic waste utilization and conserve the environment. Figure 10 shows a graphic of data that has been taken from Science Advances (published by sciencemag.org), wherein plastic waste generation and disposal has been studied and projected up to 2050. It shows that over 25 billion of plastic waste will be generated in the next 30 years, with only a small portion being recycled, a larger portion being discarded or incinerated.

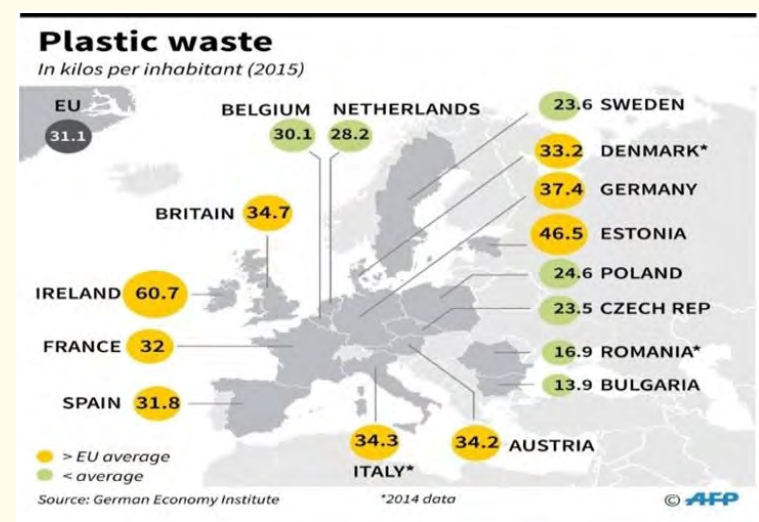

Figure 9: Map showing plastic waste generated per inhabitant (in kilograms) in Europe in 2015

(Source: Davis and Ding 2018@ phys.org).

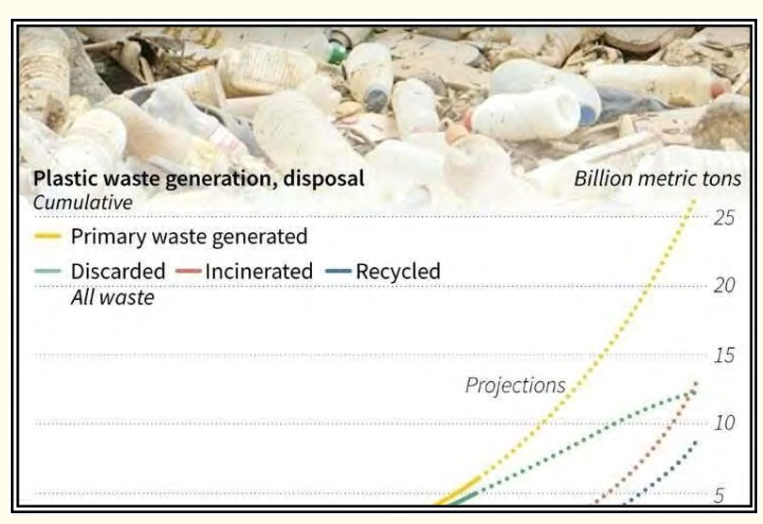

Figure 10: Plastic waste generation and disposal (Source: Guglielmi, G 2017 @sciencemag.org).

\section{The Chinese connection}

Recycling rates have been surging with the soaring of consumption rates and the development of economies all over the world, and this sounds good because not only does recycling diverts waste from the municipal landfills but also it prevents use of virgin resources that are getting scarcer. The aim is to create a circular economy, where materials used are recovered to incorporate them into production of new materials.

According to Morawski [8], China has been the dominant market for most of the world's recycled materials. She said that in 2016 alone, Chinese manufacturers and recyclers imported 7.3 million 
metric tons of waste plastics (valued at $\$ 3.7$ billion) from developed countries, including the EU, Japan, the U.K., the U.S. China also took in more than half of the world's exports of waste paper. In Marowski's article (2017), she further said that this demand for large quantities of material with little concern for quality (because low cost Chinese labour could sort it to specification) spurred a massive growth of municipal recycling programs in both Europe and North America; these programs collected a wide range of materials, including plastics Nos. 3-7, or "all plastics." Materials recovery facilities increased in number as did their average annual throughput capacities. Business was booming, and the circular economy was moving along nicely, with much of the actual recycling happening in the world's most populous country. Recently, however, China has decided to ban importation of recyclable materials because, according to the China's Ministry of Environmental Protection, in its WTO filing, they have found large amounts of dirty wastes or even hazardous wastes that are mixed in the solid waste that can be used as raw materials, which polluted China's environment seriously. To protect China's environmental interests and people's health, they have urgently adjusted the imported solid wastes list, and forbid the import of solid wastes that are highly polluted".

With this banning of imports of recyclable wastes by China, which recycles about $50 \%$ of the world's recyclable materials (NY Times, 2018), recycling activities in the world have been greatly impacted, for now. For example, in Britain and the rest of the western world, plastic wastes that have been collected for recycling (several thousand tons of them) have nowhere to go. The solution for them is to store them for now, while the solution is being sought out.

What happens then, to all the plastic waste if China will stop accepting them for recycling? In EU, regulators are trying to figure out ways to increase plastic waste recycling after the China ban took effect and huge amount of plastic waste set to sail for China have been stranded in ports. Amid the crisis brought about by the Chinese ban on plastic waste imports, the European Commission is trying to find ways to resolve the problem of having too much plastic waste. It is also looking towards other emerging economies to bring their plastic waste to for recycling.

In the Philippines, the China ban on import has affected the waste pickers and junk dealers who depend on recyclable materials recovery for livelihood. However, recycling is still very much alive and waste pickers are still doing their daily work of collecting recyclable materials from the disposal facilities and transfer stations since there are now a few recyclers in the Philippines, using plastic waste and paper waste. Their activities of materials recovery from discarded waste is helping to divert a huge percentage of waste that would otherwise eat up a lot of landfill space. Such waste diversion helps to prolong the life span of the disposal facility and improve waste management by taking much of the recyclable materials from the municipal solid waste stream. For example, in Cebu City's transfer station, there are at least sixty-five (65) waste pickers gleaning recyclables from the discarded waste being brought to the Inayawan transfer station where waste is transferred from Barangay vehicles to large hauling trucks for proper disposal. One waste picker said that they glean about $1 \%-2 \%$ recyclable for every $100 \mathrm{kgs}$ of waste brought into the transfer station. Figure 11 shows a photo of an activity of waste pickers during normal operations at the Inayawan transfer station.

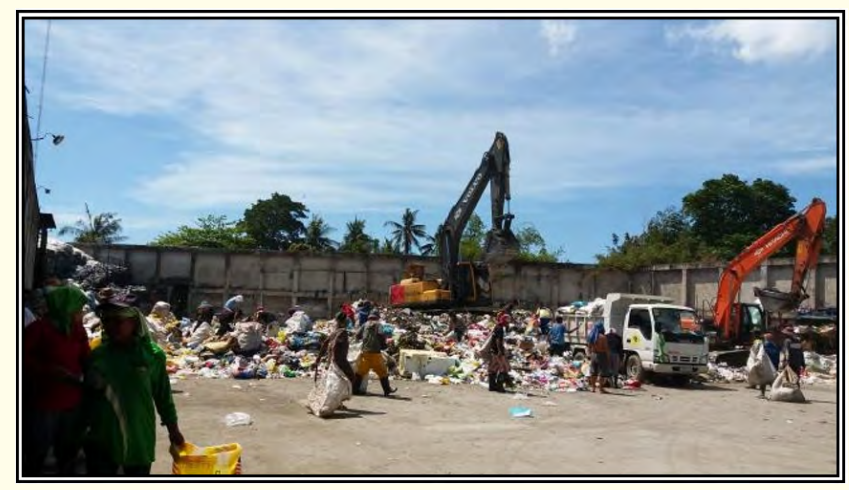

Figure 11: Waste pickers collecting recyclable materials from the transfer station.

To help the country in recycling some of its plastic waste, major consumer goods companies (Figure 12) have formed an environmental coalition last December 2017, named the Philippine Alliance for Recycling and Materials Sustainability (PARMS).

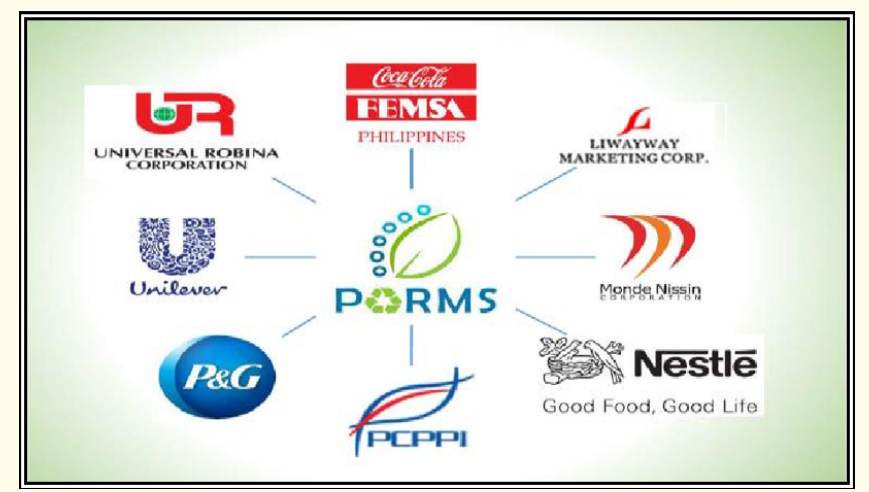

Figure 12: Corporations that formed the PARMS 
The coalition plans to build a Php25 million recycling facility for plastic sachets in the Philippines. This facility is planned to be equipped with technology designed to process over 150 metric tons of waste annually, into pallets to create school chairs and other products [9]. The objective of PARMS is to develop and implement a holistic and comprehensive program to increase resource recovery and reduce landfill dependence towards zero waste. The concept adopted is a full resource recovery and recycling program [10].

\section{The future of recycling}

One often wonders where all these recycling will lead us to. Will products in the future be entirely made of recycled materials? How are we going to handle all these wastes eventually? These are important points to ponder. In the recycling world, they will always need waste to recycle. However, as long as there are people walking on the earth, there will always be some kind of waste. This is a cycle, which should lead us all to a circular economy, where we treat waste as a resource, instead of waste that is thrown away and discarded.

Here, we will take again the ubiquitous plastics, that product, which has caused us so much convenience but has become the scourged of humanity. Plastic waste is proving to be a burden to us all. According to Callari [11] in his article Pondering the Future of Recycling, said that business will persevere but in a different form. His ideas are that (1) Recycled resin prices must be decoupled from prime resin prices, (2) Recyclers will become more sophisticated, (3) Bigger companies will get involved (and that is what's happening now), (4) There will be room for the small players, and that (5) Retailers will have a role in the recycling industry.

What about other products, for example, paper? One thing that could be said about paper is that it comes from plants. To manufacture good quality paper, pulp must come from virgin sources. In other words, they have to cut down trees to get materials for making paper. The good thing about this is that they would have to plant more trees to have a source of materials for good quality paper. This does not mean, though, that they will not recycle paper. Paper recycling has come along way. And there are many products that are produced from recycled paper, such as toilet papers and cardboard boxes. They also biodegrade in time. Due to the high recyclability of paper, recovery rates are increasing for paper waste. In the United States, they now have a goal of trying to exceed recovery rates by $70 \%$ [12]. In Europe, in 2008, recycling rate was at 66.6\% despite the economic slowdown [13]. According to this book, recovered paper provides for essential raw material for the European Paper and Board Industry and if the industry is to survive, supplies of this material must be protected, nurtured and developed in a manner which is analogous to the management of forestry resources used for production of timber and pulp.
There are a lot of challenges to overcome, but the trend is towards improvement of recycling in all stages to meet sustainable goals. The recycling industry should involve the all the stakeholders, providing IEC for awareness raising, continuous research to develop better technologies to recycle waste products, which are essentially material supply for other products. There will always be limitations on how products can be recycled, but for humanity to survive and lead sustainable living, there should be continuous action in order to manage MSW successfully.

\section{Recycling for the future}

Why do we need to recycle? As the population growth has steadily increased, so did household wastes that end up in disposal facilities. The increasing needs of the increasing population has led to the depletion of natural resources and the accompanying environmental degradation have greatly created ecological imbalance, which is unsustainable. It is therefore imperative at this point that we should push further recycling programs and activities to recover materials that will be lost if we keep on discarding them. At present, solid waste generation has greatly increased, which has put a strain on waste disposal facilities all over the world. The impact of solid waste disposal facilities to the environment are all negative as it not only causes contamination of soil and water, but also contributes to greenhouse gas emissions (methane and carbon dioxide). Recycling takes away a huge volume of discarded materials away from landfills and create "raw materials" for other products. It saves the already depleted source of virgin materials and conserve resources for future generations. For example, Lakewinds Food Co-op in Minnesota (USA) reported diverting waste per store in 2017 [14]. According to this article by Rainey, the store has diverted 37. 97 tons of waste in Richfield, 28.05 tons of waste in their Chanhassen store, 34.40 tons of waste in their Minnetonka store. This diversion was made possible by the collaboration of shoppers and employees of Lakewinds store. This is just an example to show how recycling can be a sustainable activity, with the collaboration of stakeholders, aside from the fact that it contributes to better solid waste management. In the process, they have saved the following resources in one store (Richfield) alone: 52,000+ kW-hours or electricity (enough to power 4 homes for a year); 375 mature trees (enough to produce 4,641,138+ sheets of paper); 201,757 gallons of water (enough to meet the freshwater needs of 2,690 people); 126 cubic yards of landfill airspace (enough airspace to meet the disposal needs of a community of 162 people); Prevented 109 metric ton of GHG Emissions [14].

All over the world, there are many actions in order to create better recycling opportunities. EU and Japan, for example, has forged greater opportunities for recycling [15-20]. 


\section{Conclusions}

As municipal solid waste being generated is increasing, municipal disposal facilities are burdened. It is just logical that recovery of recyclable materials be increased to divert a portion of this waste away from the municipal solid waste stream that end up in landfills. For example, biodegradable waste can be converted into compost or be used for bio-methanation to create energy. The benefits of waste diversion for recycling cannot be overemphasized. The limited space for waste disposal is being consumed at a faster pace. Increasing recovery of discarded materials is the only way forward not only to conserve precious resources but also to extend the lifespan of all disposal facilities, conserve energy, and minimize greenhouse gas emissions, among others. Recycling provides an opportunity to help change the mindset of people. To change for the better and to create a more livable and sustainable world. Recycling is among the best strategies to manage solid waste and divert them away from landfills and incinerators.

\section{Recommendations}

Recently, awareness regarding environmental issues has been increasing such that people are now more aware of their ecological footprint than before. However, it takes enforceable environmental policies and tough implementation and enforcement to be able to succeed in solving this MSW problem. To be able to carry out programs for recycling, the following are recommended:

1. Local government must enact local policies to increase recovery and strictly enforce them.

2. Private and public sector must come together to set up recovery centers so people will have a place to bring their recyclables to. It does not make sense to make people recycle when there are no recovery centers.

3. NGOs, private and public sector must work together to increase the campaign on awareness regarding recovery and recycling of discarded materials.

4. The supply side should continue to do research on how to recycle packaging waste.

5. Governments must initiate formal recycling programs in partnership with the private sector to increase recovery of recyclable materials.

6. Citizens must get rid of their throw-away habits and be more socially conscious when discarding their waste.

\section{Bibliography}

1. USEPA. Getting up to speed. Groundwater contamination (2015)

2. Sanusi AL. Groundwater quality assessment at Olusosun landfill, Lagos, Nigeria. Master's Thesis (2006).
3. Mor., et al. "Leacheate characterization and assessment of groundwater pollution near municipal solid waste landfill site" (2006).

4. NSWMC. "Draft National Solid Waste Management Status Report 2008-2015” (2017).

5. Szaky T. We can recycle everything we use including cigarette butts and toothbrushes. So why don't we? (2016).

6. "Germany recycles more than any other country" (2017).

7. Le Balnc R. "Recycling facts and figures” (2017).

8. Morawski C. In my opinion: it's time for recycled contents mandate (2017).

9. Layug MC. "Environmental coalition to build P25- million facility to recycle plastic waste in Metro Manila” (2017).

10. Lao C. Undated. Industry efforts on marine litter diversion.

11. Callari J. "Pondering the future of recycling” (2016).

12. Cleiland J. "The future of paper recycling" (2015).

13. Stawicki B and Reads B. The Future of Paper Recycling in Europe: Opportunities and Limitations (2016).

14. Rainey J. 2017 recycling reports and practices (2017).

15. Yolin C. "Waste Management and Recycling in Japan Opportunities for European Companies (SMEs focus)" (2015)

16. Compactor Management Company. 2018. Processes, stages and benefits of plastic recycling.

17. Davis B and Ding L. “China's waste import ban upends global recycling industry" (2018).

18. Guglielmi G. In the next 30 years, we'll make four times more plastic waste than we ever have (2017).

19. OECD. Recycling for the future. Sustainable development and extended producer responsibility (2017).

20. Roqoff, MJ and Ross DE. The future of recycling in the United States (2016).

Volume 3 Issue 8 August 2019

(C) All rights are reserved by Grace P Sapuay. 